\title{
Quantitative Analysis of the Internet Economy
}

\author{
Zhuo $\mathrm{Yu}^{1}$ \\ ${ }^{1}$ Graduate School of Arts and Sciences, Boston University, Brookline, Massachusettes, 02215, US
}

\begin{abstract}
Since the beginning of the 21 st century, China has made great strides in the development of the Internet, which has had an extensive and far-reaching impact on the economy and society. This has led to a growing number of scholars' attention paid to issues related to the Internet and economic development. The Internet provides a superior information platform for all economic entities, enabling economic exchanges to transcend the constraints of time and space. And on the basis of expanding the scope of transactions, reducing transaction costs, it deepens the social division of labor, creating more job vacancies, which is one of the crucial driving forces of economic development in the new era, whose role has been irreplaceable: On the one hand, as an important symbol of the knowledge economy era and the main carrier of information life, the Internet serves as the bearer of the development of a new industry - the Internet industry, making it grow and expand at an alarming rate and transform into a new force in China's industry, injecting vitality into economic growth; besides, the Internet, by virtue of its information platform and technological advantages, has brought opportunities and changes to traditional industries in many aspects. As can be seen, it is no longer possible to study economic growth without paying attention to the role of Internet factors. Therefore, this paper builds an economic growth model, selects appropriate variables and data, studies the magnitude of Internet development's contribution to the economy, and discusses the characteristics of the Internet's economic promotion effect under the analysis of the current situation, characteristics and trends of China's Internet development.
\end{abstract}

\section{Introduction}

Internet technology has already infiltrated into all walks of life. Work life or study, as well as the development, application or innovation of technology, requires the support of Internet technology. The Internet has not only improved productivity, but has also helped people to collect and process big data and massive productions. In today's world where network technology is constantly being refined and deepened, there are also more professionals involved in the business of developing and researching Internet technology, in the hope of uncovering the greater economic value of the Internet and providing support and protection for the further improvement of Chinese people's living standards and the healthy, rapid and sustainable development of the national economy. The Internet economy and the Internet industry are inextricably linked. The Internet, as the medium of production activities and daily life, plays an irreplaceable role in boosting the development of all fields in terms of direction and level. In turn, without the rise of the information industry, there would be no development of information technology or Internet economy. The Internet enables the sharing and utilization of resources through the collection, organization, processing, storage and output of information data, providing a platform for the development of the economy and connecting producers and consumers closely, which improves productivity as well as the level of production and upgrades the industrial structure. Through the discussion of the development of the Internet economy, this paper explores the quantitative economic growth and the long-term development of China's economy.

\section{Analysis of the Mechanisms of Internet Development and Economic Growth}

Analysis of current global economic indexes shows that the Internet is an important driver of economic development. Economic growth, however, is the result of a combination of multiple factors, so our study of the mechanisms of economic growth should take into account the effects of multiple factors. With the complexity of the global and regional economic environment and the deepening of global and regional economic research, the study of economic growth in our country has shifted from traditional analytical methods to the study of factors of production such as productivity. The development of the Internet touches on all aspects of economic and social development and, in terms of its impact on economic growth, there are three main channels of action.

\subsection{Forster innovation}

The endogenous growth theory, which advocates that Internet development drives economic growth by

*Corresponding author's e-mail: yuzhuo@bu.edu 
fostering innovation, considers the generation and distribution of ideas and information as a key driver of economic growth. Internet development accelerates economic growth by facilitating the development and adoption of innovation processes. The massive growth in Internet use is likely to affect the economy's ability to innovate by creating knowledge spillovers, developing new products and processes, and fostering competitive business models. First, the use of the Internet can accelerate the diffusion of ideas and information, and the efficient and low-cost dissemination of information can promote the adoption of new technologies designed by others, thereby contributing to economic growth. Secondly, it is also conducive to the emergence of new business and entrepreneurial cooperation models that rely on the spatial exchange of large volumes of information, thereby advancing the process of competition and innovation. Finally, the Internet has the potential to increase market transparency, further increasing competition and facilitating the development of market mechanisms. The development of market mechanisms is conducive to promoting the free flow of economic factors, improving the efficiency of factor allocation and reducing transaction costs, thus promoting economic growth.

\subsection{Expand consumption}

The Internet promotes economic growth by expanding consumption while the growth of e-commerce needs to be based on the Internet. The rapid development of the Internet in China has created a favorable environment for the development of e-commerce and the expansion of online shopping. According to iResearch's annual data of $\mathrm{O} 2 \mathrm{O}$ e-commerce, the transaction scale of China's ecommerce market reached 16.2 trillion yuan in 2015 with an increase of $21.2 \%$. at the same time, Taobao's "Double 11 Shopping Carnival" transaction volume grew from 52 million in 2009 to 120.7 billion in 2016, an increase of 2321 times in seven years. Such a strong growth is a testament to the huge potential of Internet development to drive residential consumption. Consumption, as one of the troika driving economic growth, has become increasingly prominent in its contribution to economic growth. Especially in the context of the new economic normal, the development of the Internet will play an even more important role in driving consumption growth and thereby promoting economic development.

\subsection{Chain growth of related industries}

The Internet contributes to economic growth by facilitating the development of related industries. The development of the Internet has not only influenced the Internet industry itself, but also combined with traditional industries through innovation and integration to form "Internet+", which has played an important role in leading economic development, promoting social progress and pushing forward innovation. First, with the development of the Internet, a series of new Internet-based industries have emerged, including Internet infrastructure services, content services and e-commerce, forming new forms of
Internet industries such as cloud services, digital economy, sharing economy and cross-border e-commerce. The development and expansion of the Internet industrial system has enlivened the national economy, boosted the development of related industries and helped promote economic transformation and upgrading. Secondly, the Internet is combined with traditional industries to accelerate industrial transformation and upgrading. The development of the Internet not only changes the industrial sales system through e-commerce, but also builds a new type of agricultural production and management system by combining with agriculture, boosts the intelligentization and networking of industrial production by integrating with the manufacturing industry, and constantly innovates the Internet financial service model by integrating with the financial industry, profoundly changing the production system, financing system and circulation system of the entire national economy, which is conducive to the transformation and upgrading of China's economy under the background of the new economic normal and supply-side reform. Statistics show that by the end of December 2016, the number of listed Internet companies in China and abroad reached 91, with a total market capitalization of $\$ 5.4$ trillion. China's Internet economy has reached $7 \%$ of the gross national product (2014), and Internet consumption has become a new engine to drive national economic growth.

\section{Economic models}

The impact of the Internet on the national economy is wide-ranging, encompassing all fields, levels and links, and it has contributed to the sustained growth of the national economy. This effect is measured here using the Cobb-Douglas production function model. C-D Adjustment of the production function according to economic theory, aggregate social product; Y. aggregate social capital; K. aggregate social labor. There is a functional relationship between $\mathrm{L}$ and the technology level $A$ as follows: $Y=f(A, K, L)(1)$. In the above production function formula, technology level $\mathrm{A}$ is a difficult factor to determine. However, the reality of economic development shows that the emergence and rapid development of the Internet has had a tremendous impact on economic activity, both directly and indirectly. Therefore, it can be argued that as the Internet continues to penetrate into all areas of economic activity, changes in the level of technology have a lot to do with changes in the level of development of the Internet. Given this understanding, the Internet factor should be included in the process of changing technology levels. If $\mathrm{A}_{0}$ is the non-Internet technology level, and $\mathrm{I}$ is the Internet development factor, then the technology level A can be expressed as: $A=A_{0} \operatorname{Ir}(2)$ where $\mathrm{r}$ is the production elasticity of Internet. According to the Cobb-Douglas production function, the model $\mathrm{Y}=\mathrm{f}(\mathrm{A}, \mathrm{K}, \mathrm{L})$ can be expressed in the following multivariate regression: $Y=A_{0} \operatorname{Ir} K^{\alpha} L^{\beta}$ Since the production function studies 
the production process from the perspective of factor supply, the Internet factor in the production function mainly refers to the supply of Internet resources. The status of Internet resources, however, encompasses a variety of distinct and interrelated types. IP addresses, domain names, websites, web pages, international outlet bandwidth are now the main indexes of Internet resource state, which can reflect the supply of Internet resources in many aspects of the Internet resource index.

Table1. Number of Internet Resources

\begin{tabular}{c|c|c|c|c}
\hline & $\begin{array}{c}\text { IP addresses } \\
\text { per 1,000 } \\
\text { people } \\
\text { (number of } \\
\text { addresses) }\end{array}$ & $\begin{array}{c}\text { Domain names } \\
\text { per 1,000 } \\
\text { people (number } \\
\text { of domains) }\end{array}$ & $\begin{array}{c}\text { Websites } \\
\text { per 1,000 } \\
\text { people }\end{array}$ & $\begin{array}{c}\text { International } \\
\text { outlet } \\
\text { bandwidth per } \\
1,000 \text { people } \\
\text { (Mbps) }\end{array}$ \\
\hline Late 2002 & 490.7 & 15.9 & 63 & 1587 \\
\hline Mid-2003 & 508.4 & 15.4 & 68 & 2684 \\
\hline Late 2003 & 521.5 & 14.9 & 75 & 3423 \\
\hline Mid-2004 & 584.4 & 17.5 & 7.2 & 6218 \\
\hline Late 2004 & 637.7 & 19.7 & 7.1 & 7918 \\
\hline Mid-2005 & 655.3 & 21.7 & 6.6 & 8060 \\
\hline Late 2005 & 670.2 & 23.4 & 6.3 & 12262 \\
\hline Mid-2006 & 689.3 & 24.1 & 6.4 & 17413 \\
\hline Late 2006 & 715.5 & 30.0 & 6.2 & 18737 \\
\hline Mid-2007 & 729.9 & 56.7 & 8.1 & 19281 \\
\hline Late 2007 & 644.1 & 56.8 & 7.2 & 17568 \\
\hline Mid-2008 & 625.1 & 58.7 & 7.6 & 19515 \\
\hline Late 2008 & 608.3 & 56,5 & 9.7 & 21486 \\
\hline Mid-2009 & 606.6 & 48.1 & 9.1 & 22117 \\
\hline Late 2009 & 605.3 & 43.8 & 8.4 & 22562 \\
\hline
\end{tabular}

As for data on the distribution of weights for each index from The 25th Statistic Report of China Internet Network Development State, see the following table:

Table2. Weighting of indexes of Internet Resources

\begin{tabular}{c|c|c|c|c}
\hline & $\begin{array}{c}\text { Number of IP } \\
\text { addresses }\end{array}$ & $\begin{array}{c}\text { Number of } \\
\text { domain } \\
\text { names }\end{array}$ & $\begin{array}{c}\text { Number of } \\
\text { websites }\end{array}$ & $\begin{array}{c}\text { Number of } \\
\text { international } \\
\text { outlet bandwidths }\end{array}$ \\
\hline Weighting & 0.3005 & 0.2435 & 0.2727 & 0.1833 \\
\hline
\end{tabular}

After standardizing the Internet resource indexes, the weights in Table 2 are used to sum the indexes, and the final Internet resource index is shown in the table below.
Table3. Data for each variable in the production function model

\begin{tabular}{c|c|c|c|c}
\hline & $\begin{array}{c}\text { Internet } \\
\text { resource } \\
\text { index }\end{array}$ & $\begin{array}{c}\text { Fixed asset } \\
\text { investment } K \\
\text { (Billions of yuan) }\end{array}$ & $\begin{array}{c}\text { Number of } \\
\text { workers L }\end{array}$ & $\begin{array}{c}\text { GDP } \\
\text { (Billions of } \\
\text { yuan) }\end{array}$ \\
\hline Late 2001 & & 28329.7 & & \\
\hline Mid-2002 & & 30721.56 & & \\
\hline Late 2002 & 100 & 33117.42 & 73740 & 117208.3 \\
\hline Mid-2003 & 115 & 33480.55 & 74086 & 123083.6 \\
\hline Late 2003 & 127 & 33843.68 & 74432 & 128958.9 \\
\hline Mid-2004 & 166 & 34787.82 & 74816 & 135461.7 \\
\hline Late 2004 & 191 & 35731.95 & 75200 & 141964.5 \\
\hline Mid-2005 & 195 & 36013.38 & 75512.5 & 149369.9 \\
\hline Late 2005 & 246 & 36294.81 & 75825 & 156775.3 \\
\hline Mid-2006 & 308 & 36567.15 & 76112.5 & 165466.4 \\
\hline Late 2006 & 333 & 36839.5 & 76400 & 174157.5 \\
\hline Mid-2007 & 389 & 41407.66 & 76695 & 186012.64 \\
\hline Late 2007 & 361 & 45975.82 & 76990 & 197867.78 \\
\hline Mid-2008 & 386 & 51929.69 & 77235 & 117726.46 \\
\hline
\end{tabular}

Output $\mathrm{Y}$ is represented by GDP; Internet factor I in technology level A is represented by Internet resource index; capital investment $\mathrm{K}$ is represented by fixed assets investment; labor input is represented by number of workers L. The Cobb-Douglas production function containing the Internet resource index, which can be expressed as: GDP Given the lag between investment and the generation of benefits, capital $\mathrm{K}$ is substituted for the previous year's data in the formula. Due to the initialization of the factors that make up the index in the calculation of the Internet development index, the corresponding initialization of GDP, Capital $\mathrm{K}$ and Labor $\mathrm{L}$ is also applied. That is, using GDP labor I in 2002 and capital $\mathrm{K}$ in 2001 as the base year, and comparing GDP capital $\mathrm{K}$ and labor $\mathrm{L}$ in each year, constructing the corresponding index form. Therefore, the variables in the above form of the production function are adjusted as follows: GDP. /GD=Ar (KK" (L/) R where the subscript

" 0 " indicates the base year and the subscript while " $\mathrm{t}$ " indicates each year of study. If $\mathrm{GDP} / \mathrm{GDP}=\mathrm{GDPK} / \mathrm{K}=\mathrm{K} * \mathrm{I} / \mathrm{l}=\mathrm{L}$, the production function can be written as: GDP $=\mathrm{fAK}^{*}$ " LP.

Take the logarithm of both sides to get: bGDP $=\ln +$ rl $\alpha \mathrm{K}-+\beta \mathrm{n}$ ". In this regression model, the matrix of Pears correlation coefficients for the explanatory variables $\mathrm{b}, \mathrm{IK}$, is shown in the following table:

Table4. Correlation Coefficient Matrix of Explanatory Variables

\begin{tabular}{c|c|c|c}
\hline & $\mathrm{hI}$ & wK $^{*}$ & $\mathrm{hL}^{*}$ \\
\hline $\mathrm{hI}$ & 1.0000 & 0.8909 & 0.9403 \\
\hline $\mathrm{hK}^{*}$ & 0.8909 & 1.0000 & 0.9848 \\
\hline $\mathrm{hL}^{*}$ & 0.9403 & 0.9848 & 1.0000 \\
\hline
\end{tabular}

As can be seen, there is a strong collinearity in the model, so the ordinary least squares method cannot be directly applied to the model to estimate the parameters.

\section{Quantitative analysis}

\subsection{Background of analysis}

Economic development requires the maintenance of a reasonable scale and proportion in all sectors and areas in order to ensure the coordination and sustainability of economic activities. The development of the Internet needs to be closely coordinated with economic 
development, and this coordination is manifested by: on the one hand, economic development should favorably facilitate the development of the Internet; on the other hand, the Internet should also be maintained at an appropriate scale and level of development so as to play a role in the promotion of economic development.

\subsection{Method of analysis}

The GM $(1,2)$ model is used here to analyse the coordination relationship between the Internet and the national economy. GM $(1,2)$ is a Grey system model with a 1 -order differential equation and 2 variables. The basic form of the model is as follows: $x(0) 1(\mathrm{k})+\alpha Z(1) 1(\mathrm{k})=$ $\mathrm{bx}(1) 2(\mathrm{k})$ whose whitening equation is: $\mathrm{dx}(1) 1 \mathrm{dt}+$ $\mathrm{aX}(1) 1=\mathrm{bX}(1) 2$ (11) where, $\mathrm{x} 1$ is the system behavior variable, and $\mathrm{x} 2$ is the system action variable. $\mathrm{x}(0) \mathrm{i}(\mathrm{n})$ (13) where the superscript (0) of " $\mathrm{X}$ " denotes the original data sequence, and the subscript $\mathrm{i}$ of $\mathrm{X}$ denotes the $\mathrm{i}$-th variable. $i=1,2 \times(1)$ where $i$ is a sequence generated by adding up $\mathrm{x}(0)$ i once. $\mathrm{x}(1) \mathrm{i}(\mathrm{k})=\sum \mathrm{nk}=1 \mathrm{x}(0) \mathrm{i}(\mathrm{k})(14)$. Generally, a is called the development coefficient of GM $(1,2)$, and a negative value of a indicates that $\mathrm{x} 1$ is gaining momentum; $b$ is the coefficient of coordination of the system effect variable on the system behavior variable and the sign of $b$ is referred to as the coordinated polarity (coordination) of the system action variable sequence $\mathrm{x} 2$ for the behavior variable sequence $x 1$. A positive value of $\mathrm{b}$ means that $\mathrm{x} 2$ facilitates the development of $\mathrm{x} 1$ whereas a negative value of $b$ means that $x 2$ constrains the development of $x 2$. 2. Coordination between Internet and GDP. Two separate models are needed to analyze the coordination of Internet and GDP based on the GM $(1,2)$ model: Model 1: using the GDP index (GDP*) as the behavior variable and the Internet resource index as the function variable; Model 2: Using the Internet resource index as the system's action variable, and the GDP Index as the system's action variable. The eight years from 2010 to 2018 are divided into two time periods, and the GDP index and Internet resource index are substituted in the GM $(1,2)$ model to examine the coordination between Internet development and GDP in these two time periods. It is clear from Models 1 and 2 that the development of GDP needs to be further strengthened relative to the development of the Internet; likewise, the development of the Internet needs to be strengthened in relation to GDP growth. The development of GDP and the development of the Internet have a positive effect on each other, as the level of GDP development and the level of Internet development need to be further improved. From Model 1, it can be seen that the GDP development has a positive momentum, but the development of the Internet has a restraining effect on the GDP development; from Model 2 , it is clear that the development trend of the Internet needs to be further strengthened, and the GDP has a certain role in promoting the development of the Internet. Internet indexes and economic growth.

\section{Internet Indicators and Economic Growth}

In order to investigate the differences and characteristics of the impact of various Internet indexes on economic growth, the number of Internet users, the number of websites and the number of $\mathrm{CN}$ domain names (all under logarithm processing and denoted as 11, I2 and I3 respectively) are used to replace the original positions of the Internet development index in the model, and the regression results are shown in Table 1 . The regression results show that, among the three major indexes of Internet development, the number of Internet users and the number of $\mathrm{CN}$ domain names, with the exception of the number of websites, have a significant effect on economic growth. As for the number of websites, which is an index of basic Internet resources, as well as the number of $\mathrm{CN}$ domain names, the correlation coefficient between the two variables is high, which may be due to the strong collinearity between the two variables affecting the regression results. Therefore, if eliminating the variable that is not significant in the original regression, i.e., the number of websites, and regressing the model again, it would yield the results shown in the second column of Table 5 .

It can be seen that the coefficients of the variables in the regression are almost the same as in column 1, with very small differences. In terms of coefficient size, the growth in the number of Internet users is a very significant boost to the economy. In the second column, the output elasticity of the number of Internet users is 0.0371 , indicating that a $1 \%$ increase in the number of Internet users leads to an increase in GDP of $0.0371 \%$, other things being equal; in comparison, the output elasticity of $\mathrm{CN}$ domain names is only 0.0180 , which indicates that the number of $\mathrm{CN}$ domain names in China is relatively low despite its rapid growth.

\begin{tabular}{|c|c|c|c|c|}
\hline $\begin{array}{c}\text { Explanatory } \\
\text { variable }\end{array}$ & 1 & 2 & 3 & \\
\hline Time period & $2000-2010$ & $2000-2010$ & $2000-2004$ & $2005-2009$ \\
\hline InK & 0.44 & 0.44 & 0.473 & 0.387 \\
\hline LnH & 0.293 & 0.293 & 0.134 & 0.396 \\
\hline InTech & 0.0787 & 0.0787 & 0.0731 & 0.0613 \\
\hline 11 & 0.0374 & 0.0371 & 0.0291 & 0.0298 \\
\hline 12 & -0.00188 & & & \\
\hline 13 & 0.0184 & 0.018 & 0.00984 & 0.0201 \\
\hline M & 0.0181 & 0.0181 & 0.0225 & 0.0258 \\
\hline Tran & 0.000481 & 0.000487 & 0.00131 & 0.00962 \\
\hline cons & 0.711 & 0.705 & 1.994 & 0.49 \\
\hline Model & Fixed effect & Fixed effect & Fixed effect & Fixed effect \\
\hline Within-R2 & 0.9911 & 0.9911 & 0.9814 & 0.9911 \\
\hline Observation & 330 & 330 & 150 & 150 \\
\hline The thid & and fourth & columns & $0 f$ Table & show \\
\hline
\end{tabular}

The third and fourth columns of Table 5 show the results of the time-varying regressions so that it is possible to study the changes in the two aspects of the Internet indexes over time. In 2000-2004, the output elasticity of 
the number of Internet users is 0.0291, while the output elasticity of the number of $\mathrm{CN}$ domain names is 0.00984 , and the coefficient of the number of $\mathrm{CN}$ domain names is not significant. In 2005-2009, the elasticities are 0.0298 and 0.0201 , respectively, which shows that the elasticity of each index has increased as the number of Internet users and the number of $\mathrm{CN}$ domain names have grown, both providing a stronger impetus to the economy. Among them, the output elasticity of growth $\mathrm{k}$ of the number of Internet users is relatively less, and combined with the characteristics of the growth of the number of Internet users, the driving effect of the number of Internet users on the economy shows a more moderate and stable performance. The elasticity of $\mathrm{CN}$ domain names varies greatly. In the first period, the elasticity is 0.00984 , which is not significant, while in the second period, the elasticity reaches 0.0201 , which is thoroughly significant.

\section{Conclusion}

The rapid development of the Internet has driven and promoted China's economic growth. Measurements show that a $1 \%$ increase in the Internet Resource Index leads to a $0.0452 \%$ increase in GDP. However, the effect of the Internet on GDP growth differs significantly in different periods due to different trends of Internet development. The trend of growth in the Internet resource index before 2006 is quite clear, and therefore the effect on GDP growth is also significant. GDP growth due to the Internet has been above $2.5 \%$, and even close to $5 \%$ in 2004 . The growth of the Internet resource index declines after 2006 and even goes negative in 2009. The effect of the Internet on GDP growth is also beginning to fade. During this period, the growth rate of GDP due to the Internet is below $1.5 \%$, and the negative growth of the Internet resource index in 2009 contributes to the negative growth of GDP. The GM $(1,2)$ model analysis also shows that during the period 2002-2005, the development of the Internet and GDP are in coordination, while the growth of GDP and the growth of the Internet need to be further strengthened. During the period 2006-2009, the growth of the Internet has weakened and the Internet has had a restraining effect on GDP growth. The development of the Internet depends on the development of the economy, and at the same time, the development of the Internet should also meet the needs of economic development so as to provide strong development conditions for economic development. After 2006, especially in 2019, the development of the Internet has lagged behind the development of the national economy, with an obvious mismatch between the development of the Internet and economic development in terms of scale, speed and breadth. Therefore, there is a need to further promote the development of the Internet, strengthen the resources needed to support the development of the Internet, and expand the scope of Internet applications.

\section{References}

1. Liu W.X and Zhang P.Y. Analysis on the Regional Differential of the Internet Diffusion in China [J]. Scientia Geographica Sinica, 2013, 23(4):398 406.

2. $\mathrm{Yu}$ L.P. Research on the Index System for the Measurement of Chin's Internet Development Level [J]. China Business and Market, 2015, (12):32-34.

3. Yu L.P. The Study on Contribution of Information Resource to Economy Growth Based on Panel Data $[\mathrm{J}]$. New Technology of Library and Information Service, 2015, (12):74-77.

4. Liu G.F. Spatio-Temporal Analysis of Regional Internet Development in China [J]. Progress in Geography, 2016, 25(4): 108-117.

5. Xie P. and Zou C.W. A Study on Internet Based Finance Model [J]. Journal of Financial Research, 2012, (12):11-12.

6. Wang J. Opportunities and Challenges Facing the Internet Industry [J]. Macroeconomics, 2003, (7):4950 .

7. Zhou H.D. The Network Industry Operation and Management [M]. Beijing: Economic and Management Publishing House, 2005:20-55.

8. Rao W.M., Zhou T.M., Wang H.Q. and Kong S. A Strategic Choice for Tapping the Effective Demand of Internet Industry [J], Management World, 2008, (1):182-183.

9. Xiang R.M. Input-output Analysis of the Impact of Internet Industry on the National Economy[J]. Statistics \& Decision, 2008, (11):75-77.

10. Liu M.H. An Empirical Study on the Organization of China's Internet Industry [D]. Hubei: Wuhan University Press, 2011. 